\title{
Sistema para distribuição integrada de contêineres cheios e vazios
}

\author{
Denise Lindstrom Bandeira UFRGS \\ João Luiz Becker UFRGS \\ Denis Borenstein UFRGS
}

\section{RESUMO}

Este artigo apresenta um modelo de rede integrado combinando realocação de contêineres vazios e operações de transbordo de contêineres cheios e vazios, visando auxiliar gestores no tratamento do desequilíbrio normalmente existente entre quantidades de contêineres de exportação e de importação. Na rede, os nós representam clientes, companhias de leasing, portos e depósitos em terra; os arcos representam rotas de transporte. 0 modelo matemático subjacente opera em estágios. Primeiro, a demanda de contêineres vazios é ajustada, considerando suprimentos e demandas globais. A seguir, um modelo de transbordo determina a solução de mínimo custo, utilizando programação linear. Os roteiros de transporte são registrados e controlados dinamicamente, repetindo os estágios ciclicamente, para um dado horizonte de tempo. 0 modelo é flexível, permitindo a configuração de vários parâmetros. Um sistema de simulação foi implementado utilizando parâmetros gerados aleatoriamente, a fim de avaliar a complexidade do modelo, testar diferentes soluções e verificar a formulação matemática.

\section{PALAVRAS-CHAVE}

Distribuição de contêineres, transporte, programação linear, heurísticas, sistema de apoio à decisão.

\section{An empty and full containers integrated distribution system}

\begin{abstract}
This paper presents an integrated network model combining empty containers assignment, and empty and full containers transhipment operations, aiming to help managers to deal with the typically unbalanced trading export and import containers. In the network, nodes represent customers, leasing companies, harbors and warehouses; while arcs represent transportation routes. The underlying mathematical model operates in stages. First, the demand for empty containers is adjusted, considering global customers supplies and demands. Next, a transhipment model determines the minimal cost solution, using linear programming. The transportation routes are registered and dynamically controlled, cycling through the stages, for a given time horizon. The model is flexible, allowing several parameters to be configured. A simulation system was implemented using randomly generated parameters, to evaluate the model's complexity, to test different solutions, and to verify the mathematical formulation.
\end{abstract}

\section{KEY WORDS}

Containers distribution, transportation, linear programming, heuristics, decision support system. 


\section{INTRODUÇÃO}

O contêiner revolucionou o transporte de cargas. Desde sua introdução, nos anos 1960, o volume de cargas transportadas em contêineres cresceu a ponto de se tornar a parcela mais significativa do tráfego de mercadorias. O uso de contêineres facilitou muito as operações de manipulação em portos e em outros pontos de transferência, aumentando a eficiência e a velocidade do transporte, e permitindo que múltiplas unidades de carga fossem manipuladas simultaneamente.

Os contêineres oferecem várias vantagens, entre elas a padronização do carregamento, aumento da segurança e facilidade de manipulação para o transporte intermodal. Por outro lado, apresentam problemas específicos tais como dimensionamento e gerenciamento de frota, decisão entre propriedade ou arrendamento dos contêineres, reposicionamento de contêineres que foram liberados e preparação anterior a um carregamento. $\mathrm{O}$ alto custo de aquisição, manutenção, manipulação e transporte de contêineres faz com que o seu gerenciamento seja um problema de grande relevância (DEJAX; CRAINIC, 1987). A partir da década de 1990, com a globalização da economia mundial, a conteinerização do comércio naval tem sido ainda mais intensificada (CHEUNG; CHEN, 1998). Entretanto, o comércio internacional é tipicamente desequilibrado: algumas áreas são predominantemente de importação e outras, de exportação. Esse desequilíbrio cria certos desafios logísticos no gerenciamento de contêineres vazios (LAI; LAM; CHAN, 1995).

O objetivo deste artigo é apresentar um modelo que auxilie a resolução do problema da alocação de contêineres vazios integrada à distribuição de contêineres cheios, de forma eficiente, levando em consideração a minimização dos custos envolvidos bem como o pronto atendimento aos clientes, a fim de otimizar métodos atualmente utilizados. Para tanto, foram utilizadas técnicas de pesquisa operacional, mais especificamente um modelo de transbordo estático, com a inclusão de procedimentos heurísticos para escalonamento e integração dinâmica dos fluxos de contêineres cheios e vazios.

Este trabalho está organizado da seguinte forma: na seção 2 é apresentado o problema de alocação e movimentação de contêineres vazios e cheios; a seção 3 traz a descrição do modelo integrado; a seção 4 descreve os procedimentos de execução dinâmica; a seção 5 trata da implementação computacional e do desempenho do modelo e, finalmente, na seção 6 são apresentadas as conclusões e as contribuições esperadas.

\section{O PROBLEMA DE ALOCAÇÃO E MOVIMENTAÇÃO DE CONTÊINERES VAZIOS E CHEIOS}

Embora contêineres cheios tenham prioridade de alocação, contêineres vazios não podem ficar parados, pois são necessários para novos carregamentos. O problema da alocação dinâmica de contêineres vazios consiste em realocar contêineres disponíveis e em determinar a quantidade que deve ser arrendada, a fim de atender a demanda de clientes, dentro de um determinado período de tempo. No caso das companhias navais marítimas internacionais, esse problema ocorre no contexto do gerenciamento da distribuição em terra e das operações de transporte. Envolve despachar contêineres vazios em resposta a requisições de clientes de exportação e reposicionar outros contêineres em depósitos ou portos para armazenagem, em antecipação a demandas futuras. 
planejamento a longo prazo da distribuição de contêineres vazios para uma companhia de navegação, utilizando modelos de otimização de rede.

Como exemplo de modelagem separada do fluxo reverso, há o trabalho de Kroon e Vrijens (1995), que apresenta um sistema logístico de devolução para contêineres retornáveis. Cheung e Chen (1998) desenvolveram um modelo de rede dinâmico para alocação eficiente de contêineres vazios, reduzindo os custos de arrendamento e o nível de estoque em portos, utilizando um modelo de rede estocástico em dois estágios. O estudo de Choong, Cole e Kutanoglu (2002) adaptou o modelo de Crainic, Gendreau e Dejax para analisar os efeitos do horizonte de planejamento no gerenciamento de contêineres vazios para redes de transporte intermodal, usando programação inteira para minimizar os custos relativos à movimentação. Jansen et al. (2004) desenvolveram um sistema cujo objetivo era fornecer um plano de transporte eficiente com relação ao custo, levando em consideração um grande número de restrições. Wang e Wang (2007) utilizaram programação inteira para analisar a reposição de contêineres vazios usando diferentes modais de transporte em terra, considerando limitações de capacidade de armazenagem em portos e de carregamento nos modais, visando minimizar o custo global de distribuição de contêineres vazios. Lam, Lee e Tang (2007) analisaram a realocação de contêineres vazios, propondo uma heurística baseada em programação dinâmica aproximada. Em problemas simplificados (dois portos e duas viagens), para os quais a solução ótima pode ser obtida, a heurística mostrou-se competitiva com outras heurísticas encontradas na literatura.

incipientemente. Shintani et al. (2007) integram os problemas de roteamento de navios de contêineres e de reposicionamento de contêineres vazios, formulando o problema em dois estágios, tratado por heurística baseada em algoritmo genético.

O trabalho de Agarwal e Ergun (2008) apresenta um modelo integrado, resolvendo um problema de escalonamento de navios e roteamento de cargas simultaneamente. Dada a complexidade da formulação em programação linear inteira mista, os autores empregam métodos heurísticos, geração de colunas e decomposição de Benders para a solução do problema, apresentando experimentos para 20 portos e 100 navios.

No Brasil, foram encontradas dissertações de mestrado relacionadas a contêineres vazios. Barco (1998) propôs um modelo de programação linear, auxiliado por um modelo de previsão de estoque, apontando o posicionamento ótimo de contêineres vazios, visando o menor custo. Rezende (2003) incrementou o trabalho de Barco implementando um modelo matemático para decisões referentes a reposicionamento e leasing de contêineres vazios, minimizando o custo envolvido. Pereira Júnior (1999) analisou uma empresa de navegação operando em um cenário de desequilíbrio nos fluxos de importações e exportações, desenvolvendo um modelo de simulação para determinação das melhores políticas de estoque e movimentação de contêineres vazios. Souza (2001) descreveu o problema de alocação de contêineres (marítimo e terrestre), apresentando algumas alternativas de estratégias de solução. Sampaio (2001) baseou-se no trabalho de Lai, Lam e Chan (1995) para gerar um programa computacional para simulação de um problema de alocação de contêineres vazios típico, a fim de fornecer suporte à decisão. Yaguiu (2006) desenvolveu um modelo de programação linear para estimar o tamanho ótimo da frota de contêineres próprios e arrendados, usando a relação entre

Usando uma concepção original, Li et al. (2004) abordaram a distribuição de contêineres vazios em um porto, antecipando sua falta ou abundância, tratando-a como um problema de estoque com demandas positivas e negativas ao mesmo tempo, utilizando uma função custo que penaliza o estoque positivo. Li et al. (2007) estenderam o modelo para multiportos, desenvolvendo heurísticas para gerenciar o desbalanceamento e a realocação de contêineres vazios, próprios ou arrendados, em portos dominantemente de importação ou de exportação.

Como constatado pela análise da literatura, problemas de contêineres são diversos e numerosos, usualmente tratados separadamente. Algumas integrações têm sido propostas, custos de aluguel e de manutenção de contêineres próprios, usando simulação e programação linear.

Não foram encontrados na literatura muitos trabalhos na área de gerenciamento de contêineres vazios, fato registrado por diversos autores (CHOONG; COLE; KUTANOGLU, 2002; LI et al., 2007). Além disso, Fleischmann et al. (1997) observaram a existência de poucos modelos tratando distribuição normal e reversa simultaneamente, comentando que a integração de ambos os canais tem sido considerada apenas no estágio de projeto da rede.

A principal contribuição deste trabalho é a elaboração de um modelo de gerenciamento integrado da distribuição e alocação de contêineres cheios e vazios. 


\section{MODELO INTEGRADO DE ALOCAÇÃO E MOVIMENTAÇÃO DE CONTÊINERES}

Antes da construção do modelo integrado, foi necessário modelar o fluxo de um contêiner vazio (desde seu descarregamento nas dependências de um destinatário até que esteja novamente disponível a um cliente, independentemente de sua localização), e de um contêiner cheio (desde seu carregamento nas dependências de um cliente até que seja entregue a um destinatário). Após a elaboração desses fluxos, eles foram integrados, observando o balanceamento entre o fluxo normal e o fluxo reverso.

Para representar a movimentação de contêineres, vazios e cheios, o modelo de roteamento foi derivado do problema clássico de transbordo (AHUJA; MAGNANTI; ORLIN, 1993). Os contêineres não são enviados de uma origem diretamente a um destino, podendo circular por quaisquer outros pontos intermediários (portos ou depósitos em terra), que também atuam como pontos de armazenagem, até chegar ao seu destino final. Os contêineres vazios podem ser transportados desde qualquer origem inicial até qualquer destino final, dependendo apenas das demandas necessárias nos pontos de destino e do suprimento disponível nos pontos de origem. Embora os contêineres cheios possuam destino específico, também são conduzidos através dos pontos de transbordo. O objetivo da movimentação de contêineres vazios e cheios é transportá-los de forma a atender a demanda de cada ponto pertencente ao modelo, visando obter o menor custo possível de transporte global.

Uma demanda de contêineres cheios para um determinado cliente pode originar uma demanda de contêineres vazios deste para outros clientes, se não houver disponibilidade. $\mathrm{O}$ modelo de alocação de contêineres vazios está embutido na rede de movimentação: os nós representam os pontos de demanda e de suprimento, e os pontos de transbordo (depósitos em terra e em portos); os arcos da rede representam os caminhos entre esses pontos. O modelo de alocação de contêineres vazios foi inspirado no modelo de Crainic, Gendreau e Dejax (1993), visando apresentar a melhor distribuição de contêineres vazios de forma a satisfazer a demanda de clientes, projetando o menor custo possível. O modelo de Crainic, Gendreau e Dejax é dinâmico e determinístico, considerando apenas um tipo de contêiner, utilizando funções lineares de custo para propriedade, substituição, empréstimo e transporte, sem considerar custos de manipulação. Por sua vez, o modelo proposto neste trabalho engloba os custos de transporte, armazenagem e processamento (manipulação) de contêineres vazios e cheios, para um tipo de contêiner, o de 20 pés, correspondente a um TEU (do inglês, Twenty-foot Equivalent Unit).

Os modelos de movimentação de contêineres vazios e cheios e de alocação de contêineres vazios foram integrados em um modelo de rede unificado, observando o balanceamento entre o fluxo normal e o fluxo reverso. A análise da rede produz um plano de rotas para redistribuição dos contêineres e atendimento da demanda de contêineres vazios e cheios, minimizando o custo total de transporte, armazenagem e processamento dos contêineres cheios e vazios, desde sua origem até seu destino, levando em consideração o suprimento disponível e o atendimento da demanda dos clientes.

\section{A interação entre os fluxos normais e os fluxos de retorno agrega complexidade aos sistemas baseados em logística reversa.}

A Figura 1 apresenta um esquema do modelo integrado, delineando a rede de movimentação de contêineres vazios e cheios. Os nós representam clientes de origem e de destino, portos, depósitos em terra, e um pool de companhias arrendatárias de contêineres. Os arcos representam as rotas possíveis entre essas entidades, que podem ser terrestres (caminhão ou trem) ou marítimas. O pool é habilitado apenas quando for definido que o modelo incorpore a opção de utilização de leasing.

Os clientes podem originar demandas de contêineres cheios ou vazios, ou fornecer suprimento de contêineres cheios ou vazios. A demanda de um cliente pode ser satisfeita a partir de qualquer cliente que possua suprimento disponível, sempre através de um depósito que esteja ligado a ambos os clientes. Os portos e os depósitos em terra processam e armazenam temporariamente contêineres em seus pátios. Por definição, não são efetuadas ligações diretas entre clientes de suprimento e clientes de demanda. Também são excluídas as combinações que representam movimentos entre o mesmo depósito em terra ou entre o mesmo depósito em porto.

\section{DINÂMICA DO MODELO}

O planejamento da distribuição de contêineres vazios é um problema combinatório cujo tamanho depende do número de clientes, portos, depósitos e demandas. Este problema torna-se mais complexo com a integração de contêineres cheios ao problema original de planejamento da distribuição. Determinar o planejamento de distribuição integrado ótimo para uma companhia de navegação, mesmo 
com poucos portos, e considerando um pequeno período de tempo, é computacionalmente explosivo e não solucionável em um intervalo de tempo razoável. Nesta seção, apresentase um método alternativo para a solução deste problema, no qual a otimalidade foi relaxada, buscando-se incorporar o máximo possível aspectos reais.

De forma a superar as dificuldades computacionais associadas à elaboração de uma solução aceitável, o problema foi decomposto em dois submodelos interconectados:

(1) Modelo estático. É responsável pela movimentação e alocação de contêineres cheios e vazios, baseado na formulação do modelo de transbordo, para cada instante de tempo $t$. É formulado com base na informação fornecida pelo modelo dinâmico, considerando demandas futuras e em transporte, localização de contêineres cheios e vazios, e estoques de contêineres cheios e vazios em cada cliente.

(2) Modelo dinâmico. Baseado nos resultados do modelo estático, controla e atualiza as demandas e os suprimentos de contêineres cheios em unidades de tempo futuras. Este modelo também define como as distintas demandas de contêineres cheios são priorizadas, despachando contêineres vazios para os nós da rede. O modelo dinâmico é baseado em métodos heurísticos.
Para descrever o relacionamento entre os dois submodelos, é necessário introduzir algumas definições e notações. Em cada instante de tempo $t$, quatro atributos devem ser controlados pelo sistema: demandas e suprimentos, de contêineres cheios e vazios. Sejam $D C_{t}^{i}$ a demanda de contêineres cheios do cliente $i$ na unidade de tempo $t, D V_{t}^{i}$ a demanda de contêineres vazios do cliente $i$ na unidade de tempo $t, S C_{t}^{i}$ o suprimento de contêineres cheios do cliente $i$ na unidade de tempo $t$, e $S V_{t}^{i}$ o suprimento de contêineres vazios do cliente $i$ na unidade de tempo $t$. É importante salientar que a demanda de contêineres vazios refere-se à necessidade de um cliente por contêineres que possam ser estufados com produtos demandados por outro cliente. O suprimento de contêineres vazios, por sua vez, refere-se à disponibilidade de contêineres vazios nas dependências de clientes, prontos para ser transportados para outro cliente, a fim de que possam ser estufados. O modelo é integrado levando em consideração que uma unidade de contêiner muda dinamicamente seu estado, conforme as necessidades dos clientes.

A dinâmica do modelo pode ser explicada considerando um ciclo no estado de uma unidade de contêiner. Assumindo que há unidades de contêineres vazios no cliente $i$ na unidade de tempo $t$, esta unidade é uma parcela do atributo $S V_{t}^{i}$. O contêiner deve ser movido para as dependências de

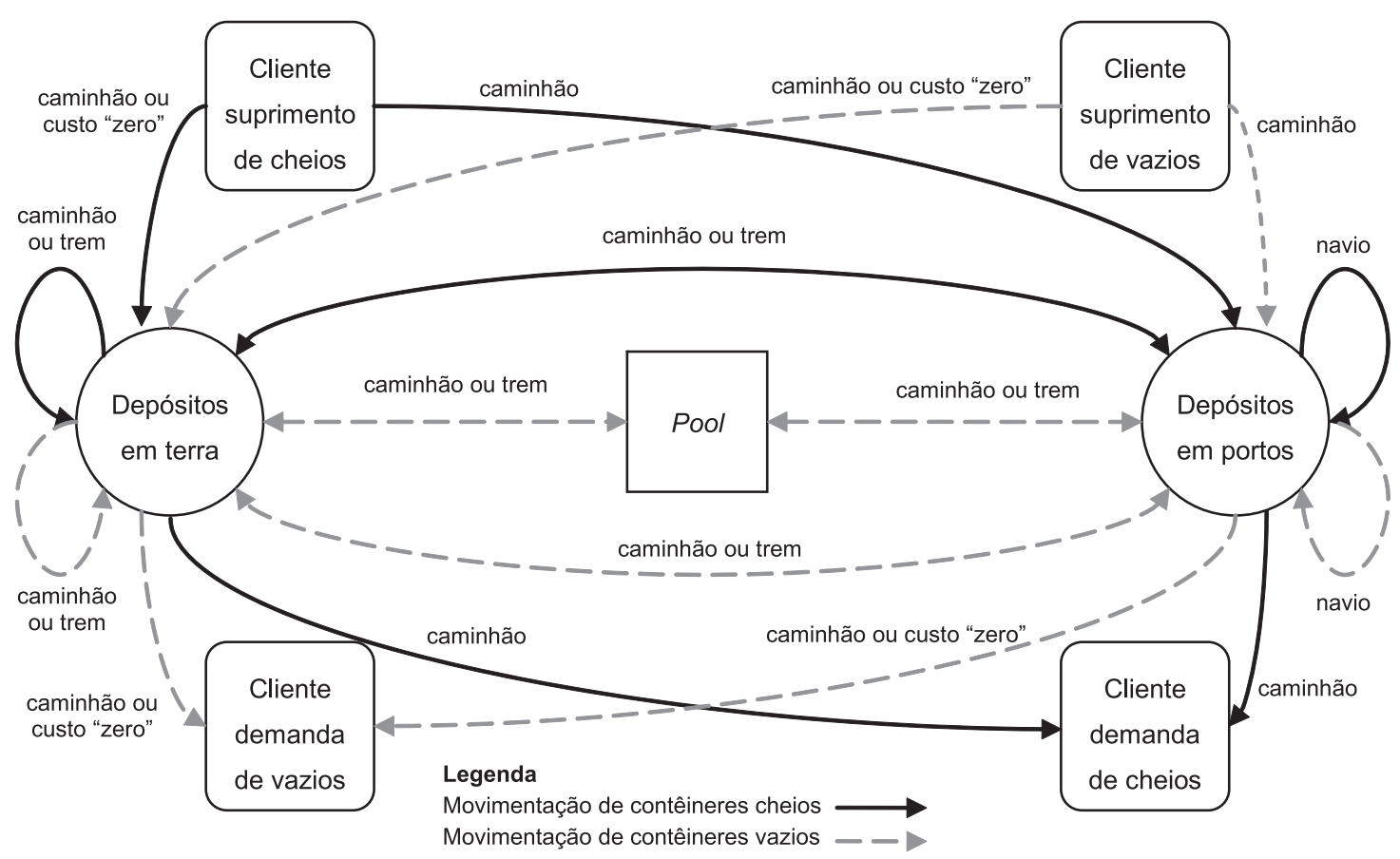

Figura 1: Fluxo de movimentação de contêineres vazios e cheios. 
outro cliente (cliente $j$ ) para ser estufado, atendendo parte de $D V_{t}^{j}$ (na realidade, $D V_{t}^{j}$ é determinado pela demanda de contêineres cheios desde outros clientes, representado pelos atributos $D C_{t^{\prime}}^{k}$, para $k \neq j$ e $\left.t^{\prime} \leq t\right)$. Após certo tempo $\sigma$, devido ao transporte, armazenagem e estufamento, o contêiner está pronto para embarcar para algum outro cliente $k$ como contêiner 'cheio', adicionando-se ao atributo $S C_{t+\sigma}^{j}$. Após certo tempo $\lambda$, devido a transporte, armazenagem e esvaziamento, o contêiner muda novamente seu estado para 'vazio', agregando-se ao atributo $S V_{t+\sigma+\lambda}^{k}$.

O modelo integrado tem seu comportamento delineado em estágios: em um determinado instante de tempo $t$ são verificadas as demandas de clientes por contêineres cheios ( $D C_{t}^{i}$, para $i \in C$, sendo $C$ o conjunto de clientes). Os supridores de produtos, na realidade os supridores de contêineres cheios $\left(S C_{t}^{i}\right.$, para $i \in C$ ), verificam a disponibilidade de contêineres vazios, a fim de satisfazer as demandas, gerando, se necessário, demandas de contêineres vazios $\left(D V_{t}^{i}\right.$, para $i$ $\in C)$. A disponibilidade de contêineres vazios $\left(S V_{t}^{i}\right.$, para $i \in C$ ) é então verificada.

A seguir, o modelo aloca contêineres vazios que devem ser transportados desde os clientes supridores até os demandantes, de forma a atender as demandas, visando o menor custo de transporte possível. O fluxo que vai de $S V_{t}^{i}$ para $D V_{t}^{j}$ corresponde a um tradicional problema de transbordo; de $S C_{t}^{i}$ para $D C_{t}^{j}$, o problema torna-se um pouco mais complexo, pois os contêineres cheios possuem origem e destino predeterminados. No próximo estágio, os contêineres vazios designados serão roteados juntamente com os contêineres cheios, satisfazendo as restrições do modelo de transbordo e buscando minimizar o custo global de transporte, armazenagem e processamento. Todos os roteiros ficam registrados e são controlados dinamicamente ao longo do tempo (a partir de $t$ ) até que os movimentos tenham sido totalmente cumpridos.

Depois que os contêineres são realocados e embarcados no tempo $t$, novas demandas por contêineres cheios são incorporadas ao modelo na unidade de tempo seguinte $(t+1)$, as quais darão origem a novas demandas por contêineres vazios, executando o modelo estático novamente. O modelo interage até que o horizonte de planejamento seja cumprido. Assim que os contêineres cheios são entregues e descarregados, ou contêineres vazios são entregues e estufados, seu estado é alterado de 'cheio' para 'vazio' ou vice-versa, e os atributos de demandas e suprimentos de contêineres cheios e vazios são atualizados.

Desta forma, os modelos de alocação de contêineres vazios e de movimentação de contêineres vazios e cheios tiveram seus fluxos e seu comportamento unificados em uma só rede, sendo tratados simultaneamente e de forma integrada.

\subsection{Descrição do modelo integrado (estático)}

A seguir, será apresentado o modelo matemático para representação do problema de alocação e movimentação de contêineres vazios e cheios de forma integrada. Sejam:

\section{Parâmetros:}

$N$ : conjunto de nós da rede, $N=H \cup W \cup S \cup D$

$H$ : conjunto de portos, $H \subset N$

$W$ :conjunto de depósitos em terra (não inclui depósitos em portos), $W \subset N$

$S$ : conjunto de clientes de suprimento, $S \subset N$

$D$ : conjunto de clientes de demanda, $D \subset N$

$A$ : conjunto de arcos da rede; em particular, $(i, i) \notin A, \forall i \in$ $N ;(i, j) \notin A$, para $i \in S$ e $j \in D$

$c_{i j}$ : custo unitário de transporte de contêineres vazios do nó $i$ ao nó $j,(i, j) \in A$

$f_{i j}$ : custo unitário de transporte de contêineres cheios do nó $i$ ao nó $j,(i, j) \in A$

$p_{i}$ : custo unitário de processamento de contêineres no nó $i$, $i \in W \cup \mathrm{H}$

$a_{i}$ : custo unitário de armazenagem de contêineres no nó $i$, $i \in W \cup \mathrm{H}$

Os custos são específicos para contêineres cheios ou vazios, embora possam ter o mesmo valor. Em cada ponto de transbordo, são também computados o custo de processamento (manipulação) e o custo de armazenagem por contêiner.

$X_{s}$ : quantidade de contêineres vazios disponível na origem $s, s \in S$

$Z_{d}$ : quantidade de contêineres vazios requerida no destino $d$, $d \in D$

$Y_{s d}: \quad$ quantidade de contêineres cheios oriunda do cliente $s$ destinada ao cliente $d, s \in S, d \in D$

\section{Variáveis de decisão:}

As variáveis de decisão do modelo são as quantidades de contêineres vazios e cheios que devem ser transportadas em cada arco da rede, observando-se que a variável referente a contêineres cheios mantém seu endereçamento (origem inicial e destino final).

$x_{i j}$ :quantidade de contêineres vazios transportados do nó $i$ ao nó $j,(i, j) \in A$

$y_{\text {irre }}$ : quantidade de contêineres cheios transportados do nó $i$ ao nó $j$, cuja origem inicial é $r$ e destino final é $e,(i, j) \in$ $A, r \in S, e \in D$

\section{Função objetivo:}

De posse dessas variáveis, a função objetivo busca minimizar o custo total de operação do sistema de distribuição e transporte de contêineres vazios e cheios. 


$$
\begin{gathered}
\text { vazios }\left[\begin{array}{l}
\sum_{s \in S} \sum_{w \in W} c_{s w} x_{s w}+\sum_{s \in S} \sum_{h \in H} c_{s h} x_{s h}+\sum_{w \in W} \sum_{d \in D}\left(c_{w d}+p_{w}+a_{w}\right) x_{w d}+\sum_{h \in H} \sum_{d \in D}\left(c_{h d}+p_{h}+a_{h}\right) x_{h d}+ \\
\sum_{w \in W} \sum_{w \in E W \mid w \neq w^{\prime}}\left(c_{w w^{\prime}}+p_{w}+a_{w}\right) x_{w w^{\prime}}+\sum_{w \in W} \sum_{h \in H}\left(c_{w h}+p_{w}+a_{w}\right) x_{w h}+ \\
\sum_{h \in H} \sum_{h^{\prime} \in H \mid h \neq h^{\prime}}\left(c_{h h^{\prime}}+p_{h}+a_{h}\right) x_{h h^{\prime}}+\sum_{h \in H} \sum_{w \in W}\left(c_{h w}+p_{h}+a_{h}\right) x_{h w}+
\end{array}\right. \\
\text { cheios } \begin{array}{l}
\sum_{r \in S} \sum_{e \in D}\left[\sum_{s \in S} \sum_{w \in W} f_{s w} y_{s w r e}+\sum_{s \in S} \sum_{h \in H} f_{s h} y_{s h r e}+\sum_{w \in W} \sum_{d \in D}\left(f_{w d}+p_{w}+a_{w}\right) y_{w d r e}+\right. \\
\sum_{h \in H} \sum_{d \in D}\left(f_{h d}+p_{h}+a_{h}\right) y_{h d r e}+\sum_{w \in W} \sum_{w \in W \mid w \neq w^{\prime}}\left(f_{w w^{\prime}}+p_{w}+a_{w}\right) y_{w w^{\prime} r e}+ \\
\left.\sum_{w \in W} \sum_{h \in H}\left(f_{w h}+p_{w}+a_{w}\right) y_{w h r e}+\sum_{h \in H} \sum_{h^{\prime} \in H \mid h \neq h^{\prime}}\left(f_{h h^{\prime}}+p_{h}+a_{h}\right) y_{h h^{\prime} r e e}+\sum_{h \in H} \sum_{w \in W}\left(f_{h w}+p_{h}+a_{h}\right) y_{h w r e}\right]
\end{array}
\end{gathered}
$$

O custo total em (1) é formado pela soma de toda a movimentação de contêineres (vazios e cheios) a partir de clientes de suprimento para depósitos, de depósitos para clientes de demanda, e entre depósitos. Definiu-se que os custos de armazenagem e de processamento fossem alocados ao final de cada arco (trecho de transporte).

\section{Restrições:}

As restrições de suprimento dos clientes do modelo são indicadas por:

$$
\begin{array}{ll}
\sum_{j \in W \cup H} x_{s j} \leq X_{s} & \text { para todo } s \in S \\
\sum_{j \in W \cup H} y_{s j s d} \geq Y_{s d} & \text { para todo } s \in S, d \in D
\end{array}
$$

Para contêineres vazios (2), considera-se o suprimento total de cada ponto de origem, envolvendo todos os pontos intermediários de destino. Para contêineres cheios (3), considera-se o suprimento de cada ponto de origem endereçado a um determinado ponto de destino, envolvendo todos os pontos de destino intermediários.

Da mesma forma, as restrições de demandas de clientes são representadas por:

$$
\begin{array}{ll}
\sum_{j \in W \cup H} x_{j d} \geq Z_{d} & \text { para todo } d \in D \\
\sum_{j \in W \cup H} y_{j d s d} \geq Y_{s d} & \text { para todo } d \in D, s \in S
\end{array}
$$

Essas restrições garantem o atendimento da demanda, de contêineres vazios (4) e de contêineres cheios (5), considerando todos os pontos intermediários de origem (depósitos em terra e em portos).

Além disso, é necessário balancear os fluxos nos nós de transbordo, expressos por:

$$
\begin{array}{ll}
\sum_{s \in S} x_{s j}=\sum_{d \in D} x_{j d} \quad \text { para todo } j \in W \cup H \\
\left(y_{s j s d}-y_{j d s d}\right)=0 & \text { para todo } s \in S, d \in D, j \in W \cup H
\end{array}
$$

Essas equações asseguram o balanceamento do fluxo de todos os contêineres vazios (6), e de todos os contêineres cheios (7), que passam por determinado ponto intermediário.

$$
\begin{aligned}
& x_{i j} \in\{0,1,2, \ldots\} \quad \text { para todo }(i, j) \in A \\
& y_{i j s d} \in\{0,1,2, \ldots\} \text { para todo }(i, j) \in A, s \in S, d \in D
\end{aligned}
$$

Por fim, são embutidas as restrições usuais de não-negatividade das variáveis de decisão para contêineres vazios (8), e para contêineres cheios (9).

Obs.: Os custos de leasing não foram considerados como logísticos, mas financeiros e, apesar de calculados e disponíveis, não são incluídos no cálculo de minimização do custo global.

\subsubsection{Dimensionamento do modelo de contêineres vazios e cheios}

Para avaliação da complexidade do modelo, após a execução de algumas simplificações algébricas foram obtidas expressões equivalentes à quantidade de variáveis que representam os contêineres vazios e os contêineres cheios do modelo.

Seja $|N|$ a cardinalidade do conjunto $N$; a quantidade de variáveis do modelo integrado de alocação e movimentação de contêineres vazios e cheios é obtida por:

$$
(|W|+|H|)[(|W|+|H|+1)(|S||D|+1)+|S|+|D|-2]
$$

E a quantidade de restrições é representada pela expressão: 


$$
(|W|+|H|)(|S||D|+1)+2|S||D|+|S|+|D|
$$

Atribuindo valores aos parâmetros dessas expressões, é possível dimensionar o número máximo de variáveis e de restrições (equações (10) e (11), respectivamente) de diferentes instâncias do modelo integrado de alocação e movimentação de contêineres vazios e cheios, evidenciando os efeitos de certas configurações para análise de sensibilidade do modelo (Tabela 1).

Analisando a tabela, percebe-se que a quantidade de variáveis e restrições relacionadas aos contêineres cheios aumenta com mais intensidade do que as relativas aos contêineres vazios, pelo fato de todos os caminhos serem multiplicados pelas diferentes combinações de origens e destinos.

Pode-se verificar, enfim, que com uma instância pequena do problema - 20 clientes de origem e de destino, e 10 depósitos (em portos e em terra), atinge-se cerca de 45.000 variáveis e 5.000 restrições, ilustrando o efeito combinatório do modelo. Essa característica aponta para a conveniência de se utilizar métodos heurísticos, abrindo mão da otimização plena (KIM; EGBELU, 1999).

\subsection{Utilização do modelo como base para implementação dinâmica}

Para a implementação dinâmica, é necessário que as demandas e os suprimentos de contêineres cheios sejam atualizados e transferidos para as próximas unidades de tempo, interligando os estágios estático e dinâmico, conforme explicado no início desta seção. Para que essa transferência fosse realizada de forma apropriada, fez-se uso de procedimentos heurísticos, que serão descritos a seguir.

\subsection{Procedimentos heurísticos de solução}

Um dos desafios enfrentados durante o desenvolvimento e testes do sistema foi encontrar uma forma eficiente de priorizar o atendimento das demandas lidando com os pedidos não atendidos das unidades de tempo anteriores (backlog). Algumas soluções causavam grande defasagem entre a data da solicitação e a data do atendimento. Se pedidos não atendidos são adiados para a próxima unidade de tempo, e o sistema prioriza demandas mais antigas, as novas encomendas ficam temporariamente relegadas. Caso todas as encomendas fossem agregadas ao modelo antes da otimização, o custo ótimo poderia fazer com que as mais novas fossem atendidas prioritariamente, e as encomendas mais antigas nunca o fossem. Portanto, optou-se por focalizar no custo, mas sem desprezar o nível de atendimento. Possivelmente, os custos de transporte poderiam ser menores, mas os gargalos no sistema o tornariam inviável.

O problema de transporte de contêineres, em situações reais, é tipicamente desequilibrado - normalmente a quantidade global de suprimento e a de demanda não são as mesmas. Entretanto, para a resolução eficiente de um problema tradicional de transbordo, é recomendável que essas quantidades sejam igualadas. Antes de montar o problema, é necessário fazer algum tipo de equiparação entre a demanda necessária e o suprimento disponível, tanto para contêineres cheios como para vazios.

\subsubsection{Ajuste da demanda de contêineres cheios}

Para cada cliente para o qual estejam sendo solicitados contêineres cheios, são respeitados os seguintes critérios

Tabela 1: Dimensionamento de variáveis e restrições com acréscimo de clientes e depósitos.

\begin{tabular}{|c|c|c|c|c|c|c|c|c|c|}
\hline \multirow[b]{3}{*}{$\mathrm{S}$} & \multirow[b]{3}{*}{$\mathrm{D}$} & \multirow[b]{3}{*}{ W } & \multirow[b]{3}{*}{$\mathrm{H}$} & \multicolumn{6}{|c|}{ Modelo } \\
\hline & & & & \multicolumn{2}{|c|}{ Contêineres vazios } & \multicolumn{2}{|c|}{ Contêineres cheios } & \multicolumn{2}{|c|}{ Integrado } \\
\hline & & & & Variáveis & Restrições & Variáveis & Restrições & Variáveis & Restrições \\
\hline 1 & 1 & 1 & 1 & 6 & 4 & 6 & 4 & 12 & 8 \\
\hline 2 & 2 & 2 & 2 & 28 & 8 & 80 & 24 & 108 & 32 \\
\hline 3 & 3 & 3 & 3 & 66 & 12 & 378 & 72 & 444 & 84 \\
\hline 4 & 4 & 4 & 4 & 120 & 16 & 1152 & 160 & 1272 & 176 \\
\hline 5 & 5 & 5 & 5 & 190 & 20 & 2750 & 300 & 2940 & 320 \\
\hline 10 & 10 & 5 & 5 & 290 & 30 & 11000 & 1200 & 11290 & 1230 \\
\hline 10 & 10 & 10 & 10 & 780 & 40 & 42000 & 2200 & 42780 & 2240 \\
\hline 15 & 15 & 4 & 4 & 296 & 38 & 16200 & 2250 & 16496 & 2288 \\
\hline 20 & 20 & 4 & 4 & 376 & 48 & 28800 & 4000 & 29176 & 4048 \\
\hline 20 & 20 & 5 & 5 & 490 & 50 & 44000 & 4800 & 44490 & 4850 \\
\hline
\end{tabular}


para priorização das demandas:

- Data original da demanda - pedidos mais antigos são priorizados, pois postergações sucessivas comprometem o nível de serviço oferecido.

- Custo de transporte - menor custo de transporte de contêineres cheios entre este cliente e o cliente que está solicitando os contêineres, pois a minimização do custo é o objetivo principal.

- Tempo de transporte - menor tempo de transporte entre este cliente e o cliente que está solicitando os contêineres, inspirado na regra de ordenamento de tarefas SPT (do inglês, Shortest Processing Time).

Quando o suprimento total disponível de contêineres não é suficiente, um desses critérios é utilizado: menor custo ou menor tempo entre os pontos de origem e destino, conforme configurado no sistema. A demanda não atendida é recalculada e repassada para a próxima unidade de tempo. É importante registrar que várias outras possibilidades de priorização foram testadas, algumas fazendo com que o sistema atrasasse muito a resolução das pendências. Este

\section{sistema possui um bom nível de parametrização, oferecendo flexibilidade de uso para avaliação} de diferentes estratégias operacionais.

método de priorização mostrou-se adequado, com boa distribuição do atendimento das demandas entre os diferentes clientes.

\subsubsection{Ajuste da demanda de contêineres vazios}

Para atender aos pedidos de contêineres vazios, não é possível utilizar o mesmo método de priorização dos contêineres cheios (menor custo ou menor tempo), pelo fato de não haver caminhos (origens e destinos) preestabelecidos para ser analisados. Optou-se, então, pelo critério de priorização de demandas de maior volume. A demanda por contêineres vazios não atendida em uma determinada unidade de tempo será incorporada ao pedido na próxima unidade de tempo, quando a demanda é recalculada adicionando as novas necessidades de contêineres, e abatendo os contêineres cheios e vazios que estão por chegar. Esse método também se mostrou adequado à resolução das demandas de forma equânime entre os diferentes clientes.

Cabe ressaltar que esses procedimentos heurísticos bastante elementares reduziram drasticamente o número de variáveis e restrições do modelo. Por exemplo, numa instância com 20 clientes, de origem e de destino, e oito depósitos, e com horizonte de 50 unidades de tempo, o número máximo de variáveis foi reduzido de cerca de 30.000 para 6.200; o número máximo de restrições, que se situava em torno de 4.000 , reduziu-se para cerca de 800 .

\subsubsection{Procedimentos de resolução do modelo inte- grado}

A solução encontrada para incorporação do fator "tempo" no modelo deste estudo foi decompor o problema em estágios, interligando seus resultados, conforme os passos descritos no Quadro 1.

\section{IMPLEMENTAÇÃO COMPUTACIONAL DO MODELO}

Após concluída a etapa de testes relativos à modelagem matemática do modelo, conferindo os resultados obtidos utilizando o software Lindo ${ }^{\circ}$, deu-se início à elaboração de um modelo executável, que representasse as diferentes entidades envolvidas no modelo e sua interação. Foi utilizado o Microsoft ${ }^{\star}$ Access para a base de dados e VBA (do inglês, Visual Basic for Applications) para os procedimentos, interagindo com o software Lindo ${ }^{\star}$ API (do inglês, Application Programming Interface) para os cálculos de minimização de custos.

Vários testes foram realizados, utilizando diversas configurações. Os resultados podem ser verificados em Bandeira (2005). A Figura 2 apresenta a visualização de trechos de roteiros de transporte que foram gerados em um determinado processamento. Na parte inferior do gráfico, pode-se acompanhar a linha de tempo (em unidades de tempo).

\subsection{Customizações (flexibilidade do modelo)}

O modelo foi desenvolvido de maneira a permitir o maior número possível de parâmetros, facilitando, desta forma, a execução de testes para análise da sensibilidade dos seus diferentes componentes. Alterações em um ou mais desses parâmetros afetam a dinâmica de todo o sistema.

São atributos parametrizáveis:

- tempo de carregamento e descarregamento de contêineres em clientes;

- estoque mínimo (de segurança) de contêineres vazios em clientes;

- margem de segurança a adicionar a pedidos de contêineres vazios (por cliente);

- tempo médio de processamento de um contêiner em um depósito; 
- tempo médio de armazenagem de um contêiner em um depósito;

- capacidade total, dos depósitos, para contêineres vazios e cheios;

- tempo médio de transporte de contêineres entre clientes e depósitos, e entre depósitos;

- prazo, em unidades de tempo, para verificação de recebimentos futuros (look ahead) de contêineres cheios para um determinado cliente, antes que este faça um pedido de contêineres vazios;

- opção de utilização ou não de leasing;

- número de unidades de tempo com demanda de contêineres vazios não atendida, antes de fazer utilização de leasing;

- prazo mínimo para devolução de contêineres arrendados;

- prazo de vencimento de operações de leasing.
Outros atributos atuam como variáveis de estado iniciais, causando pouca influência no transcorrer do processamento do sistema, sendo percebidos apenas nos primeiros estágios da execução:

- estoque inicial de contêineres vazios nos clientes;

- estoque inicial de contêineres disponíveis para arrendamento, nas companhias de leasing.

\subsection{Resultados computacionais - desempenho do modelo}

Com o objetivo de avaliar a viabilidade de processamento do modelo, foram feitas várias execuções comparativas, com opção de utilização de leasing, para um horizonte de planejamento de 100 unidades de tempo e quantidades crescentes de clientes de demanda e de suprimento, mantendo fixa a quantidade de depósitos em terra (três) e portos (três). $\mathrm{O}$ computador utilizado foi um Pentium 4 de 2,2 GHz, com 512

Quadro 1: Algoritmo de resolução do modelo integrado.

Início

Passo 1 Fazer $t=1$

Passo 2 Ajustar a demanda de contêineres vazios e cheios, considerando suprimentos e demandas globais dos clientes (balanceamento dos recursos, de forma estática, priorizando o nível de serviço)

2.1 Obter demandas de contêineres cheios de cada cliente para todos os outros clientes

2.2 Gerar demanda de contêineres vazios

$$
\begin{aligned}
\text { demanda a gerar } & =\text { demanda total de contêineres vazios } \\
& - \text { estoque mínimo de contêineres vazios } \\
& - \text { saldo atual de contêineres vazios } \\
& - \text { suprimento futuro de contêineres vazios e cheios }
\end{aligned}
$$

2.3 Obter suprimento total de contêineres vazios do sistema, calculando, para cada cliente:

$$
\begin{aligned}
\text { suprimento de contêineres vazios } & =\text { saldo atual de contêineres vazios } \\
& - \text { demanda de contêineres vazios para cliente } \\
& - \text { estoque mínimo (segurança) }
\end{aligned}
$$

2.4 Ajustar demandas e suprimentos globais, de contêineres cheios e vazios, segundo os procedimentos descritos nas seções 4.2 .2 e 4.2 .3

2.5 Se opção para utilizar leasing está habilitada então

Gerar pedidos de leasing

Efetuar devoluções de leasing

Passo 3 Determinar a solução de mínimo custo do modelo de transbordo - equações (1) a (9), considerando transporte, processamento e armazenagem de unidades de contêineres cheios e vazios

Passo 4 Registrar e controlar a dinâmica do transporte utilizando a solução encontrada no Passo 3

Passo 5

$$
\begin{gathered}
\text { Se } t<t_{\max } \quad \text { então } \\
\text { Fazer } t=t+\Delta t \\
\text { Ir para o Passo } 2
\end{gathered}
$$

Passo 6 Gerar estatísticas 
MB de memória, e o software de otimização LINDO API. Os resultados podem ser vistos na Tabela 2 .

Uma análise da tabela permite as seguintes observações:

- tempo de processamento - quase instantâneo para dois clientes até cerca de 40 minutos para 20 clientes. Levandose em conta a quantidade de relacionamentos possíveis no caso de 20 clientes, o tempo de resolução pode ser considerado apropriado;

- número máximo de variáveis e de restrições - aumentam significativamente a cada inclusão de cliente, como se pode deduzir a partir das equações (10) e (11);

- custo total de transporte, armazenagem e processamento esse valor sofre um grande incremento devido ao maior número de interações;

- demora média na entrega (média das diferenças entre as datas de recebimento e de solicitação) - a demora média passou de 12 unidades de tempo, com dois clientes, para 14,5 unidades de tempo, com 20 clientes. O incremento de clientes aumentou em pequena proporção o tempo de espera dos pedidos;

- diferença média atendimento/solicitação (média das diferenças entre contêineres solicitados e quantidades atendidas) - a diferença permaneceu em zero, até quatro clientes, sendo de 1,5 para 20 clientes. De modo geral, os pedidos estão sendo atendidos nas quantidades pretendidas, restando poucas pendências para unidades de tempo posteriores;

- ociosidade (neste caso, relação entre o total de contêineres vazios e o total de contêineres do modelo) - pode-se verificar como a razão diminui conforme a quantidade de clientes aumenta, passando de 0,9 (com dois clientes) para 0,1 (com 20 clientes). Como esperado, um maior número de clientes faz com que os contêineres não fiquem vazios por muito tempo.

\subsection{Resultados gráficos}

Conforme demonstrado anteriormente, o modelo de simulação permite testar muitas combinações diferentes entre quantidades de clientes e de depósitos, variando demandas, suprimentos, estoques iniciais, tempos de transporte, de armazenagem e de processamento, fazendo com que seja possível observar o relacionamento entre vários conjuntos de variáveis. Nesta seção, são apresentados alguns resultados na forma de gráficos (séries temporais e histogramas), com a intenção de ilustrar algumas dessas possibilidades.

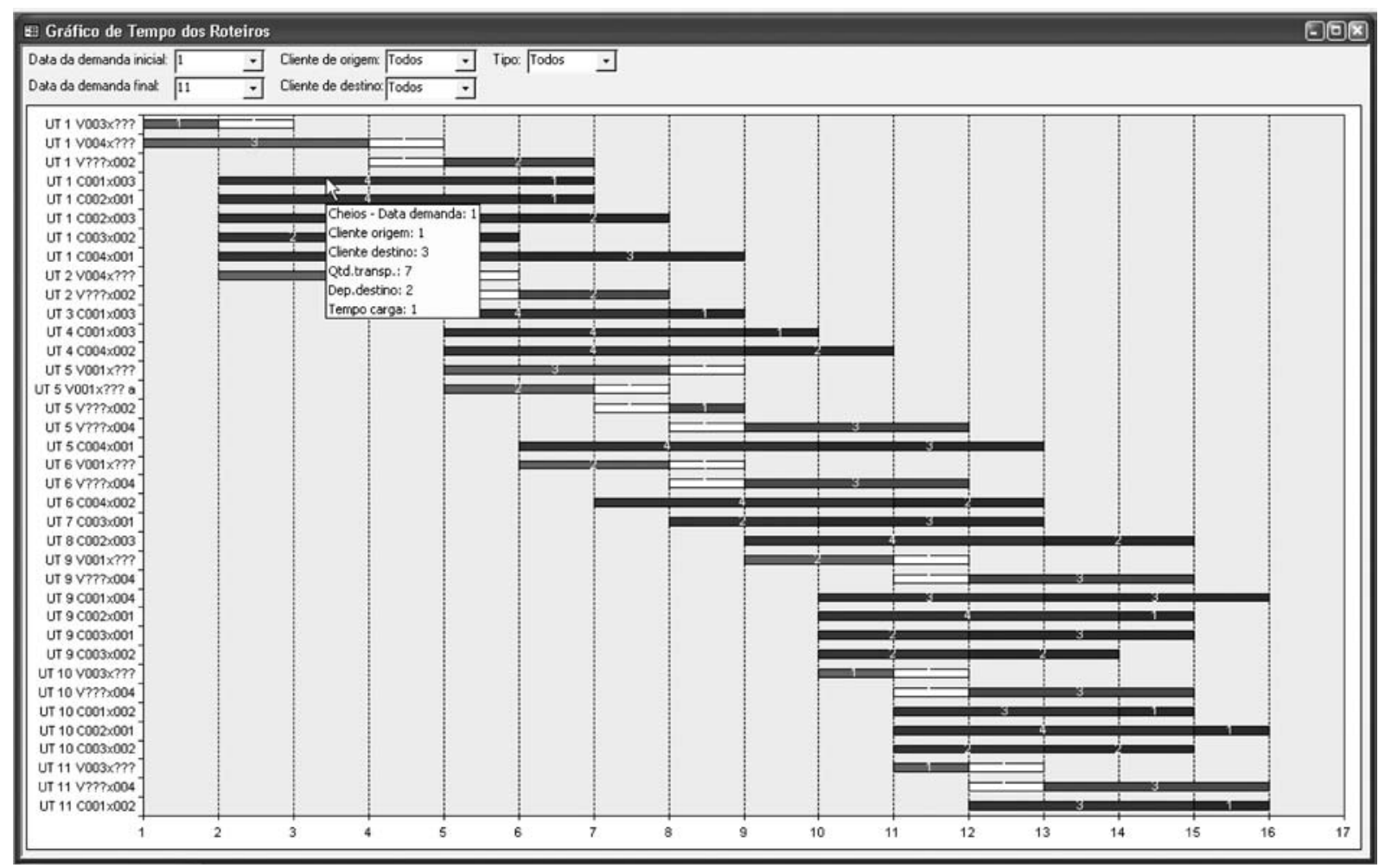

Figura 2: Gráfico de tempos de roteiros. 
Todos os gráficos apresentados a seguir são relativos a uma instância do modelo com quatro clientes de demanda e de suprimento, três depósitos (em terra ou em portos), e horizonte de planejamento de 200 unidades de tempo, sem utilização de leasing. Dados adicionais:

- custos:

- custo de transporte entre trechos: média 3,42; desvio padrão 1,93

- custo de armazenagem: média 2,20; desvio padrão 0,82

- custo de processamento: média 2,10; desvio padrão 0,82
- tempo de transporte entre trechos: média 2,3; desvio padrão 1,1

- demanda de contêineres cheios:

- probabilidade de geração por unidade de tempo: média 0,19 ; desvio padrão 0,10

- demanda mínima: média 5,8; desvio padrão 2,4

- demanda máxima: média 14,8; desvio padrão 8,0

A Figura 3 mostra que o custo médio, para contêineres cheios e para contêineres vazios, de transporte, armazenagem e processamento comporta-se de modo a estabilizar-se à medida que o tempo avança.

Para representar o prazo de entrega da demanda de

Tabela 2: Execuções comparativas para 100 unidades de tempo.

\begin{tabular}{|c|c|c|c|c|c|c|c|}
\hline $\begin{array}{l}\text { Número de } \\
\text { clientes }\end{array}$ & $\begin{array}{l}\text { Tempo de } \\
\text { execução }\end{array}$ & $\begin{array}{c}\text { Número máximo } \\
\text { de variáveis }\end{array}$ & $\begin{array}{l}\text { Número } \\
\text { máximo de } \\
\text { restrições }\end{array}$ & Custo total (1) & $\begin{array}{l}\text { Demora média } \\
\text { na entrega (2) }\end{array}$ & $\begin{array}{c}\text { Diferença média } \\
\text { atendimento/ } \\
\text { solicitação (3) }\end{array}$ & $\begin{array}{l}\text { Ociosidade } \\
\text { (4) }\end{array}$ \\
\hline 2 & 00:00:12 & 90 & 17 & 626,40 & 12,0 & 0,0 & 0,9 \\
\hline 3 & 00:00:26 & 138 & 26 & $2.359,00$ & 11,9 & 0,0 & 0,7 \\
\hline 4 & 00:00:38 & 225 & 42 & $4.378,00$ & 12,2 & 0,0 & 0,7 \\
\hline 5 & 00:00:59 & 347 & 65 & $6.202,10$ & 12,2 & 0,2 & 0,6 \\
\hline 6 & 00:01:39 & 434 & 80 & $11.141,00$ & 13,8 & 0,9 & 0,4 \\
\hline 7 & 00:01:58 & 512 & 94 & $14.655,80$ & 12,2 & 0,4 & 0,4 \\
\hline 8 & 00:02:53 & 643 & 119 & $19.217,00$ & 12,9 & 0,6 & 0,3 \\
\hline 9 & 00:03:56 & 772 & 142 & $25.702,20$ & 13,8 & 1,1 & 0,2 \\
\hline 10 & 00:05:08 & 1139 & 206 & $30.895,80$ & 13,4 & 0,8 & 0,2 \\
\hline 11 & 00:06:34 & 1219 & 220 & $38.681,40$ & 13,3 & 0,8 & 0,2 \\
\hline 12 & 00:08:20 & 1426 & 260 & $44.212,10$ & 14,1 & 1,2 & 0,2 \\
\hline 13 & $00: 10: 23$ & 1584 & 289 & $54.148,20$ & 14,2 & 1,2 & 0,2 \\
\hline 14 & $00: 12: 52$ & 2051 & 370 & $60.319,80$ & 13,8 & 1,0 & 0,2 \\
\hline 15 & $00: 15: 57$ & 2120 & 383 & $69.678,80$ & 14,0 & 1,1 & 0,2 \\
\hline 16 & $00: 21: 13$ & 2851 & 508 & $84.081,80$ & 14,0 & 1,2 & 0,1 \\
\hline 17 & $00: 25: 56$ & 4369 & 776 & $95.484,90$ & 14,1 & 1,4 & 0,1 \\
\hline 18 & $00: 31: 40$ & 4559 & 810 & $107.191,90$ & 14,2 & 1,3 & 0,1 \\
\hline 19 & $00: 35: 45$ & 4333 & 772 & $121.359,00$ & 14,3 & 1,5 & 0,1 \\
\hline 20 & $00: 40: 19$ & 5142 & 911 & $129.872,10$ & 14,5 & 1,5 & 0,1 \\
\hline
\end{tabular}

(1) custo de transporte entre trechos: média 3,71; desvio padrão 2,22; custo de armazenagem: média 2,08; desvio padrão 0,75; custo de processamento: média 2,50; desvio padrão 1,12

(2) tempo de transporte entre trechos: média 3,6; desvio padrão 1,3

(3) geração de demanda de contêineres cheios: probabilidade de geração por unidade de tempo: média 0,2; desvio padrão 0,05; demanda mínima: média 2,7; desvio padrão 1,4; demanda máxima: média 6,0; desvio padrão: 1,6

(4) ociosidade $=$ [total de contêineres vazios] / [total de contêineres] 
contêineres cheios, foi calculada a diferença entre a última data de entrega de cada pedido completo, independente de entregas parciais, e a data original do pedido. As freqüências dessas diferenças foram colocadas em um histograma (Figura 4). Pode-se observar que há pouca incidência de valores altos, indicando um bom nível de serviço.

Considerando contêineres cheios, para data original de cada pedido e seus respectivos clientes de demanda e de suprimento, foram agrupados o total de contêineres cheios solicitados e a quantidade que foi possível atender, após ajuste pelo suprimento. As diferenças entre esses valores foram acumuladas, e o valor acumulado foi dividido pelas datas originais, dando origem às médias das diferenças por data. Também foi calculado o percentual de atendimento (quantidade ajustada sobre quantidade solicitada). Esse percentual foi acumulado e dividido pela

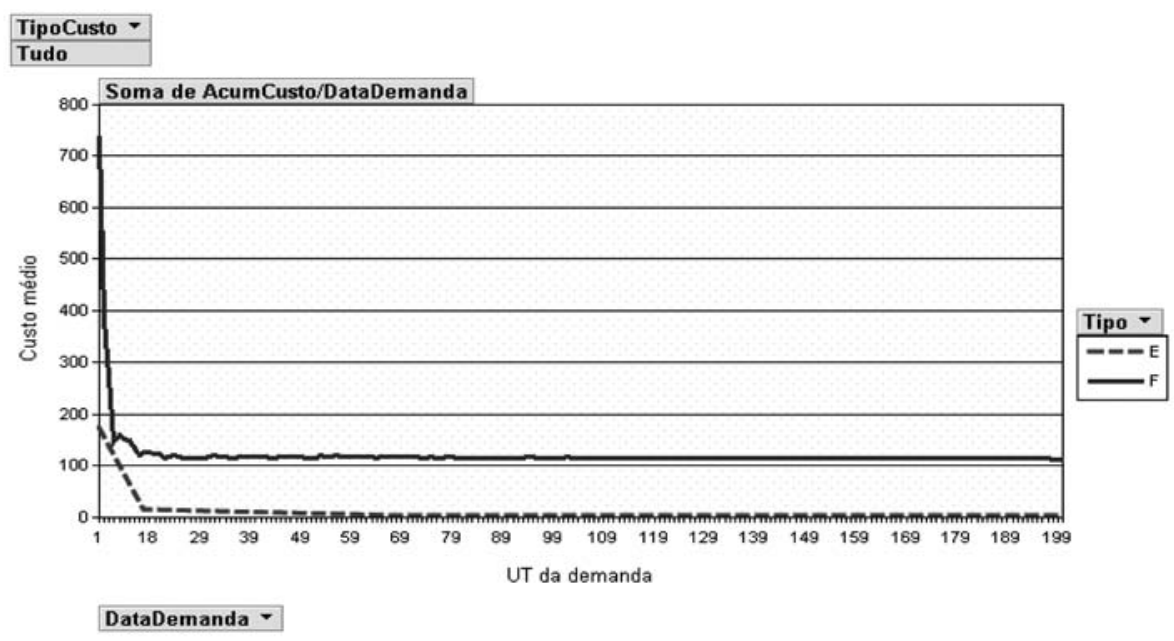

Figura 3: Custo médio por UT de transporte, armazenagem e processamento.

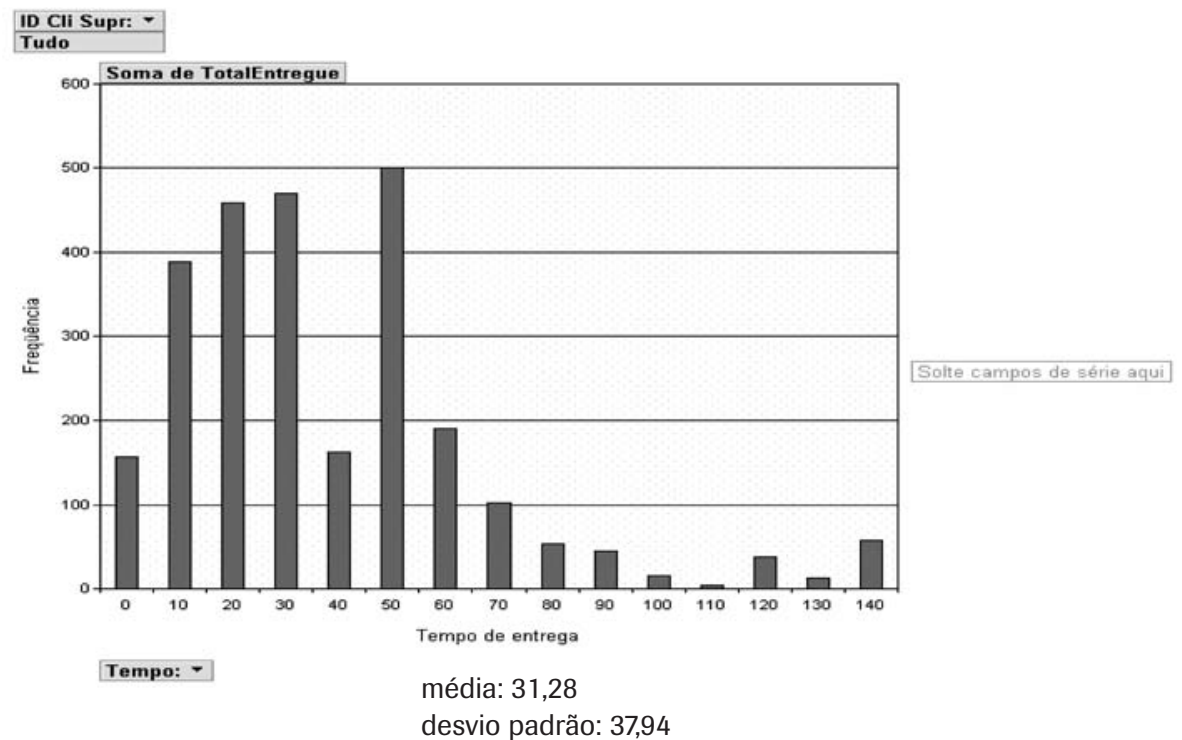

Figura 4: Histograma dos tempos de entrega de contêineres cheios. 
data original, originando o gráfico da Figura 5. Visualmente, pode-se observar que, após um período de tempo, a diferença entre a quantidade solicitada e a quantidade atendida estabiliza-se próximo a zero, indicando certo equilíbrio no sistema no atendimento das demandas de contêineres cheios.

Com relação à ociosidade do sistema, foram exploradas algumas relações entre contêineres vazios, cheios, em trans- porte e parados, verificando-se pouca flutuação no decorrer do tempo. No exemplo apresentado na Figura 6, foram ilustrados alguns desses parâmetros:

- total de contêineres vazios sobre total geral de contêineres;

- total de contêineres vazios parados sobre total de contêineres;

- total de contêineres vazios em transporte sobre total de contêineres cheios em transporte;

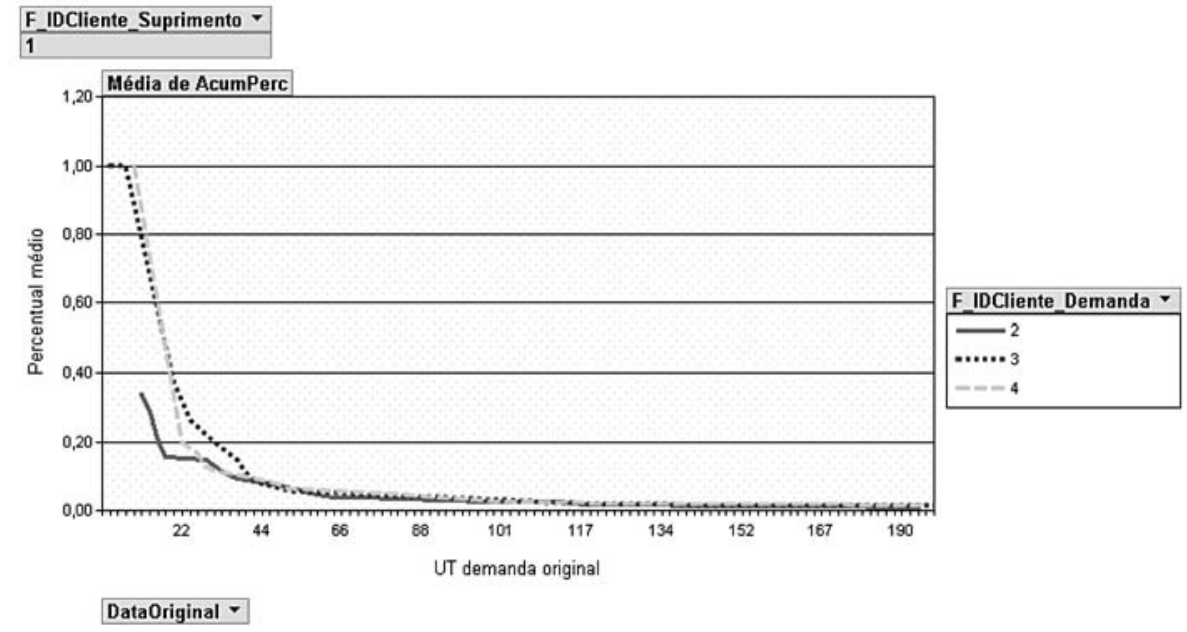

Figura 5: Percentual médio de atendimento da quantidade solicitada - contêineres cheios.

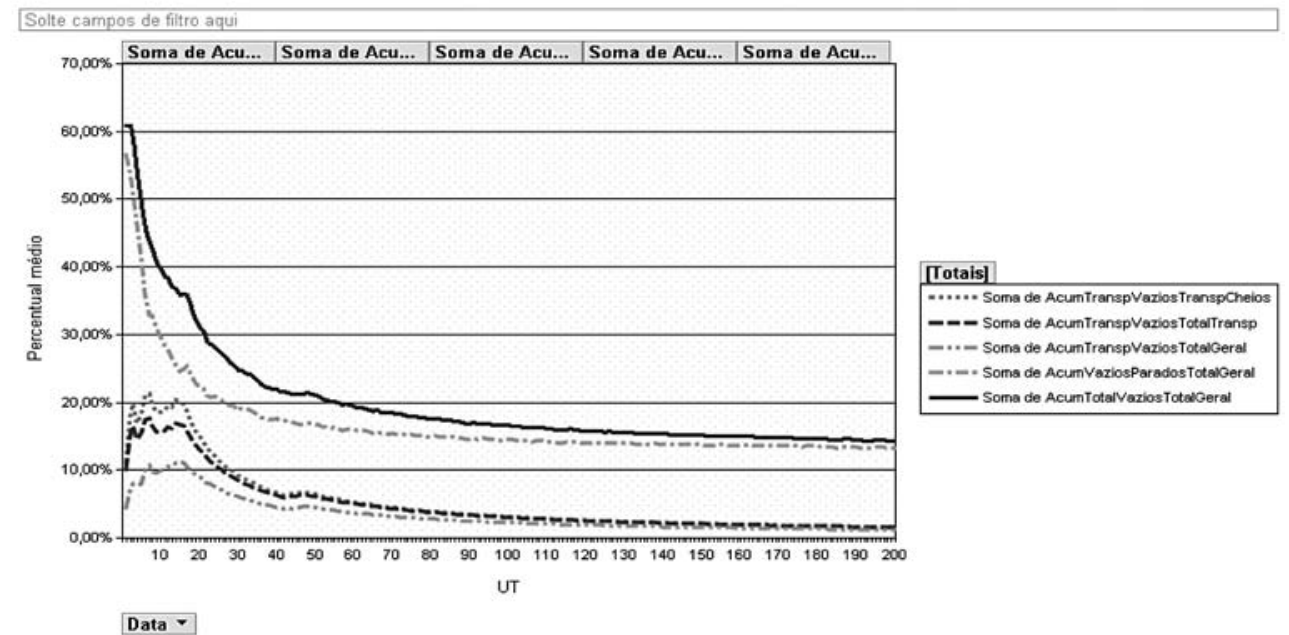

Figura 6: Ociosidade do sistema. 
- total de contêineres vazios em transporte sobre total de contêineres em transporte;

- total de contêineres vazios em transporte sobre total geral de contêineres.

Todas essas relações tenderam a um equilíbrio com o desenvolvimento das unidades de tempo. Cabe ressaltar que o custo do transporte de contêineres cheios será repassado aos clientes, enquanto que o de contêineres vazios é encargo somente da companhia de navegação.

É importante observar que esses gráficos são apenas alguns exemplos ilustrativos da potencialidade de geração de análises sobre a dinâmica do modelo. Diversos tipos de dados podem ser correlacionados fornecendo outras ilustrações gráficas sobre o desempenho do sistema. Cada cliente pertencente ao modelo pode ser analisado separadamente, sendo possível verificar datas de chegada e quantidades entregues em cada cliente, ou verificar a quantidade de contêineres cheios que cada cliente está despachando por unidade de tempo. Com relação ao transporte, é possível verificar os tempos médios e quantidades transportadas em cada trecho, analisando a capacidade dos diferentes roteiros. Também os custos de transporte, armazenagem e processamento podem ser separados para análise individual ou, ainda, individualizados por cliente.

de ser considerados simultaneamente. Como conseqüência o problema, quando modelado, apresenta natureza combinatória com relação à quantidade de variáveis e de restrições.

O modelo foi projetado em estágios, permitindo a elaboração de uma solução estática, designando os melhores caminhos e quantidades de contêineres cheios e vazios que devem ser transportados, de forma abter o menor custo (transporte, armazenagem e processamento) possível. Após cada resolução do problema de transbordo e atualização de todos os dados, transcorre a próxima unidade de tempo, quando é feita uma nova avaliação das demandas, executando novamente o modelo, e assim sucessivamente. Todas as rotas obtidas na solução de mínimo custo (estática) são registradas e controladas dinamicamente até sua chegada ao destino final.

O problema foi modelado e resolvido de forma dinâmica, abrangendo vários períodos de tempo contíguos, utilizando parâmetros determinísticos e estocásticos no suprimento e na demanda. Também foram utilizadas medidas de desempenho da rede (tempo de transporte, tempo de atendimento da demanda), indicativas do nível de serviço. Para implementação do modelo, utilizou-se formulação algébrica, otimização com técnicas de programação matemática, modelos estocásticos, simulação e técnicas heurísticas para solução de problemas em rede.

O sistema possui um bom nível de parametrização, oferecendo grandes possibilidades para testes e análises. $\mathrm{O}$ modelo permite a avaliação de diferentes políticas de alocação de contêineres, garantindo um nível de serviço adequado, identificando maneiras de reduzir os custos fixos e variáveis relativos ao comércio naval. É importante salientar que várias

Enfim, são muitas as possibilidades de ilustração na forma de tabelas, gráficos e correlações entre variáveis, sendo as aqui apresentadas apenas algumas escolhas demonstrativas da capacidade informacional que o modelo e o sistema podem oferecer. A quantidade de relacionamentos implementáveis depende, em última instância, dos interesses específicos do usuário.

\section{CONCLUSÕES}

O problema de alocação de contêineres é extremamente complexo, especialmente se o modelo busca otimizar ao mesmo tempo aspectos de custo e de nível de serviço das operações de uma companhia. A interação entre os fluxos normais e os fluxos de retorno agrega complexidade aos sistemas baseados em logística reversa, pois esses fluxos têm configurações foram testadas em diferentes execuções, sendo aqui apresentados apenas alguns exemplos. Alguns procedimentos heurísticos tiveram de ser utilizados para minimizar a quantidade de variáveis do modelo e propiciar a utilização do software disponível. A partir disso, o modelo funciona como um problema de otimização (minimização de custos).

Foi possível elaborar um modelo de previsão satisfatório, computando contêineres vazios que estão chegando em datas futuras, contêineres que estão sendo esvaziados e tornando-se disponíveis. A modelagem do estoque mínimo e da margem de correção de pedidos torna o modelo mais próximo da realidade, oferecendo mais flexibilidade aos operadores.

O sistema não apenas elabora o roteamento dos contêineres baseado no mínimo custo, mas ainda provê o controle de todas as movimentações dos trechos de transporte, computando a entrada desses contêineres novamente no sistema, de forma automática para o usuário. O leasing, embora simplificado, 
mostrou sua importância na liberação de demandas e no bom andamento do fluxo do sistema.

Quando testado com valores experimentais, o comportamento do modelo mostra-se apropriado, executando em um curto espaço de tempo e apresentando um nível de serviço adequado, com comportamento equilibrado no transcorrer do tempo.

A escolha do horizonte de planejamento foi arbitrária, tendo sido exploradas execuções com 20, 100, 200 e 1.000 unidades de tempo. Em princípio, não há limite para o horizonte de planejamento, devido ao fato de o modelo conseguir absorver novas demandas entre os estágios estático e dinâmico. Portanto, a limitação refere-se apenas à capacidade do sistema computacional disponível e à situação a ser modelada, a qual pode incluir pontos críticos que acarretem perda de desempenho do sistema.

Tratar a movimentação dos contêineres, realocar os contêineres vazios considerando o suprimento e a demanda, recalcular as demandas não atendidas, atender as demandas de contêineres cheios - na mesma unidade de tempo - é uma atividade bastante intrincada, exigindo testes exaustivos e avaliações de desempenho do sistema. Além disso, o algoritmo deve ser flexível para inclusão ou modificação de restrições e para alteração de seus critérios de apuração de custo.

Embora o modelo apresente uma complexidade $O\left(n^{4}\right)$, o sistema demonstrou eficiência em termos do número de variáveis e restrições em casos práticos, fornecendo soluções em períodos de tempo bem inferiores se comparados com especialistas.

A maior contribuição deste trabalho é a unificação de modelos que usualmente são tratados de forma isolada. O desenvolvimento de um novo modelo, integrando o fluxo de contêineres cheios com o fluxo de contêineres vazios, propiciou a implementação de um sistema de apoio a decisões com bom potencial para utilização por companhias de transporte.

\section{Artigo recebido em 07/11/2005 Aprovado para publicação em 05/08/2008}

\section{REFERÊNCIAS}

AGARWAL, R.; ERGUN, O. Ship scheduling and network design for cargo routing in liner shipping. Transportation Science, n. 42(2), p. 175-196, 2008.

AHUJA, R. K.; MAGNANTI, T. L.; ORLIN, J. B. Network flows: theory, algorithms, and applications. Englewood Cliffs: Prentice Hall, 1993.

BANDEIRA, D. L. Alocação e movimentação de contêineres vazios e cheios: um modelo integrado e sua aplicação. Tese de doutorado, UFRGS, 2005.

BARCO, B. L. A logística do contêiner vazio. Dissertação de mestrado (resumo CAPES), USP, 1998.

CHEUNG, R. K.; CHEN, C. A two-stage stochastic network model and solution methods for the dynamic empty container allocation problem. Transportation Science, n. 32(2), p. 142-162, 1998.
CHOONG, S. T.; COLE, M. H.; KUTANOGLU, E. Empty container management for intermodal transportation networks. Transportation Research Part E, n. 38(6), p. 423-438, 2002.

CRAINIC, T. G.; GENDREAU, M.; DEJAX, P. Dynamic and stochastic models for the allocation of empty containers. Operations Research, n. 41(1), p. 102-126, 1993.

DEJAX, P. J.; CRAINIC, T. G. A review of empty flows and fleet management models in freight transportation. Transportation Science, n. 21, p. 227-247, 1987.

FLEISCHMANN, M. et al. Quantitative models for reverse logistics: a review. European Journal of Operational Research, n. 103(1), p. 1-17, 1997

JANSEN, B. et al. Operational planning of a large-scale multi-modal transportation system. European Journal of Operational Research, n. 156(1), p. 41-53, 2004.
KIM, K. H.; EGBELU, P. J. Scheduling in a production environment with multiple process plans per job. International Journal of Production Research, n. 37(12), p. 2725-2753, 1999.

KROON, L.; VRIJENS, G. Returnable containers: an example of reverse logistics. International Journal of Physical Distribution \& Logistics Management, n. 25(2), p. 56-68, 1995.

LAI, K. K.; LAM, K.; CHAN, W. K. Shipping container logistics and allocation. Journal of the Operational Research Society, n. 46(6), p. 687-697, 1995.

LAM, S. W.; LEE, L. H.; TANG, L. C. An approximate dynamic programming approach for the empty container allocation problem. Transportation Research Part C: Emerging Technologies, n. 15(4), p. 265-277, 2007.

LI, J. A.; LEUNG, S. C. H.; WU, Y.; LIU, K Allocation of empty containers between multi-ports. European Journal of Operational Research, n. 182(1), p. 400-412, 2007. 
Bandeira, D. L.; Becker, J. L.; Borenstein, D. Sistema para distribuição integrada de contêineres cheios e vazios. Produção, v. 18, n. 3, p. $452-468,2008$

LI, J. A.; LIU, K.; LEUNG, S. C. H.; LAI, K. K. Empty container management in a port with long-run average criterion. Mathematical and Computer Modelling, n. 40(1-2), p. 85-100, 2004.

PEREIRA JÚNIOR, P. F. Avaliação de políticas de estoque e movimentação de contêineres vazios utilizados no transporte marítimo. Dissertação de mestrado, UFRJ, 1999.

REZENDE, L. B. A logística do contêiner vazio: uma nova abordagem. Dissertação de mestrado, USP, 2003

SAMPAIO, L. M. D. Alocação de contêineres vazios para a logística reversa do transporte de carga. Dissertação de mestrado (resumo CAPES), UFRJ, 2001.

SHEN, W. S.; KHOONG, C. M. A DSS for empty container distribution planning. Decision Support Systems, n. 15(1), p. 7582, 1995.

SHINTANI, K.; IMAI, A.; NISHIMURA, E.; PAPADIMITRIOU, S. The container shipping network design problem with empty container repositioning. Transportation Research Part E: Logistics and Transportation Review, n. 43(1), p. 39-59, 2007.

SOUZA, F. C. G. Procedimentos para a alocação de contêineres vazios no transporte. Dissertação de mestrado (resumo CAPES), PUC-RJ, 2001.
WANG, B.; WANG, Z. Research on the optimization of intermodal empty container reposition of land-carriage. Journal of Transportation Systems Engineering and Information Technology, n. 7(3), p. 29-33, 2007.

WHITE, W. W. Dynamic transshipment networks: an algorithm and its application to the distribution of empty containers. Networks, n. 2(3), p. 211-236, 1972.

YAGUIU, K. Modelo para o dimensionamento de uma frota de contêineres para uma empresa de navegação. Dissertação de mestrado (resumo CAPES), USP, 2006.

\section{AGRADECIMENTOS}

Os autores agradecem o apoio do CNPq para a realização da pesquisa que deu origem a este trabalho.

\section{SOBRE OS AUTORES}

\section{Denise Lindstrom Bandeira}

Escola de Administração

Universidade Federal do Rio Grande do Sul

End.: Rua Washington Luiz, 855 - 90010-460 - Porto Alegre (RS)

Tel.: 55 (51) 3308-3466

E-mail: dlbandeira@ea.ufrgs.br

\section{João Luiz Becker}

Escola de Administração

Universidade Federal do Rio Grande do Sul

End.: Rua Washington Luiz, 855 - 90010-460 - Porto Alegre (RS)

Tel.: 55 (51) 3308-3474

E-mail: jlbecker@ea.ufrgs.br

\section{Denis Borenstein}

Escola de Administração

Universidade Federal do Rio Grande do Sul

End.: Rua Washington Luiz, 855 - 90010-460 - Porto Alegre (RS)

Tel.: 55 (51) 3308-4053

E-mail: denisb@ea.ufrgs.br 